\title{
A angústia tratada como um afeto
}

\author{
Anguish treated as affection
}

\section{Claudia Murta}

Doutora em Filosofia pela Université de Paris VIII, professora associada do Departamento de Filosofia e do Programa de Pós-Graduação em Filosofia da Universidade Federal do Espírito Santo (UFES), Vitória, ES - Brasil, e-mail: cmurta@terra.com.br

\section{Resumo}

No ano universitário de 1962-63, Lacan, em seu Seminário, propõe a angústia como um afeto. Para ele, o afeto não é uma emoção, pois a cada vez que se referencia aos afetos na psicanálise, procura afastá-los das propostas de análise psicofisiológica e procura se aproximar da filosofia. Para tanto, ele cita filósofos tais como Jean-Paul Sartre, Martin Heidegger e Sören Kierkegaard, além de Sigmund Freud. O objetivo deste artigo é percorrer as referências lacanianas às concepções dos filósofos citados, incluindo as concepções freudianas, sobre o tema da angústia e articulá-las às proposições lacanianas sobre o mesmo tema. A partir dessa comparação poder-se-á acompanhar o motivo pelo qual Lacan prefere se referir à filosofia para abordar o tema da angústia em vez de abordá-la a partir das referências psicofisiológicas.

Palavras-chave: Angústia. Afeto. Conceito. Sinal. 


\section{Abstract}

In the academic year of 1962-62, in his Seminary, Lacan proposed to treat anguish as affection. For him, affection is not emotion, because when the affection is referred in psychoanalysis, it is attempted to put them away from the approaches of the psychophysiolocial analysis and put them together to philosophy. So, besides Sigmund Freud, he mentions philosophers like Jean-Paul Sartre, Martin Heidegger and Sören Kierdegaard. The proposal of this paper is to search through the Lacanian references to these philosophers, including the Freudian conceptions, on the theme of anguish and to articulate them with Lacanian propositions on the same theme. From this comparison we will understand the reason by which Lacan prefers to refer to philosophy in order to approach the theme of anguish instead of approaching it from the psychophysiological references.

Keywords: Anguish. Affection. Concept. Sign.

\section{A angústia é um afeto}

No seminário A angústia, de 1962-63, Lacan propõe a angústia como um afeto e a diferencia da emoção. Para ele, o afeto não é uma emoção, pois a cada vez que se referencia aos afetos na psicanálise, procura-se afastá-los das propostas de análise psicofisiológica e aproximá-los da filosofia. Assim também sucede quanto ao afeto da angústia. Para acompanhar a problemática proposta por Lacan contra as teorias psicológicas e psicofisiológicas das emoções, a leitura do texto de Jean-Paul Sartre Esboço para uma teoria das emoções, de 1939, apresenta-se bastante instrutiva.

Nesse texto, Sartre critica, entre outros, o método psicológico para a abordagem das emoções. No seu entender, o psicólogo trata a emoção como um fato e, como tal, sempre acidental. Em suas palavras: "a emoção não existe enquanto fenômeno corporal, pois um corpo não pode ser emocionado, por não poder conferir um sentido a suas próprias manifestações" (SARTRE, [1939] 2006, p. 28). Para perceber isso, o psicólogo deve, segundo Sartre, buscar algo além dos distúrbios vasculares ou respiratórios; ele deve procurar o sentido da emoção. Contra as teorias fisiológicas e funcionalistas, ele afirma que, mesmo se 
a emoção, objetivamente percebida, apresente-se como uma desordem fisiológica, como fato de consciência, ela não é desordem, ela tem um sentido. Nessa perspectiva, a emoção se apresenta como uma estrutura organizada.

O papel dos fenômenos puramente fisiológicos representa, na concepção sartreana, o caráter sério da emoção. Eles não são separáveis da conduta; compõem com esta uma forma sintética e não poderiam ser estudados por si mesmos. O erro é tentar considerá-los de maneira isolada. A emoção não é um comportamento puro, mas, sim, um comportamento que aparece em um corpo perturbado; sem essa perturbação, a conduta seria significação pura. Para Sartre, a consciência que se emociona se lança no mundo e transforma o seu corpo. A emoção não é um acidente, é um modo de existência da consciência. Sartre concebe o corpo como fruto da inter-relação entre mundo e consciência; desse modo, para ele, torna-se impossível que o corpo se comova emocionalmente sem ser aquilo de fato, sem ser consciência do que está sendo. Desse modo, destaca-se na concepção sartreana o papel preponderante da consciência na direção de tal processo. Em sua proposição: “a emoção é um fenômeno de crença”" (SARTRE, [1939] 2006, p. 77).

As objeções de Sartre esclarecem as objeções da Lacan quanto às teorias psicológicas e psicofisiológicas da emoção, pois elas caminham no mesmo sentido, de tal modo que, na introdução do seminário $A$ angústia, Lacan cita alguns filósofos, entre eles Sartre. Para Lacan, Sartre oferece um tratamento sério para o tema da angústia. Ao comentar a importância dos afetos para a psicanálise, Jacques-Alain Miller, seguindo a orientação lacaniana, aponta que:

sem dúvida, no afeto trata-se do corpo, mais exatamente dos efeitos de linguagem sobre o corpo - esse efeito, que enumerei recentemente, de recorte, de desvitalização, de esvaziamento do gozo, ou seja, segundo o termo de Lacan, de "outrificação" do corpo. E aquilo que Freud chama de separação da quota de afeto da ideia se torna para nós a articulação entre o significante e o objeto $a$. A orientação lacaniana implica, portanto, distinguir as emoções, de registro animal, vital, em seu aspecto de reação ao que ocorre no mundo, dos afetos como pertencentes ao sujeito (MILLER, 1998, p. 47). 
Nesse sentido, Lacan situa a sua própria consideração sobre a proposta freudiana quanto aos afetos. Pois Freud diferencia ideia e afeto ao formular que, entre os dois, "a diferença toda decorre do fato de que ideias são catexias - basicamente traços de memória -, enquanto que os afetos e as emoções correspondem a processos de descarga, cujas manifestações finais são percebidas como sentimentos" (FREUD, [1915] 2006, p. 183). Desse modo, para Freud, sendo um processo de descarga, um afeto não pode ser inconsciente, só o recalcado o pode. Ele ainda acrescenta no mesmo texto que "faz parte da natureza de uma emoção que estejamos cônscios dela, isto é, que ela se torne conhecida pela consciência" (FREUD, [1915] 2006, p. 182). Assim, o afeto, ou as emoções, ou os sentimentos, tal como Freud os nomeia, não podem ser recalcados, mas seguem um caminho direto para a consciência.

Na visão sartreana, a angústia é, tal como qualquer afeto na visão freudiana, consciente. Para Sartre, a angústia se caracteriza por uma conduta refletida do sujeito, na qual ele se posiciona perante as situações e se angustia diante da não determinação existente entre os motivos e o seu ato: ele experimenta, em forma de íntima vivência, a sua liberdade para agir. Nesse contexto, a angústia assinala a tomada de consciência da própria consciência. Seria, pois, a caracterização da autorreflexão do ser consciente (ou da consciência); é o homem percebendo sua condição. A angústia aparece no pensamento sartreano como um elemento que se encarrega de efetuar a tomada de consciência de todas as formas possíveis que o homem tem de agir no mundo, ou seja, a consciência da liberdade.

A concepção sartreana de homem funda-se na liberdade. Em $O$ ser e o nada, o filósofo amarra radicalmente a existência humana à liberdade ao afirmar que "não há diferença entre o ser do homem e seu ser-livre" (SARTRE, [1943] 1997, p. 68). O homem, para Sartre, é ser inacabado entregue a si mesmo, sem pré-definições, responsável pelo seu projeto de existência. Nesse sentido, todas as ações humanas são livres, porém não se esgotam no fazer de autoconstituição do sujeito; elas projetam toda a realidade.

Desse modo, o homem existe perdendo de si e atingindo o outro, o que está fora de si. É um duplo fazer, um fazer de superação que instaura o universo humano como o todo no qual o indivíduo mergulha, 
fazendo o seu ser de forma que vai do transcendental ao transcendente no movimento de busca, uma execução particular que realiza o que de fato é o humano. Se para Sartre o homem é liberdade, é por meio da angústia que ele concebe o que se é: "existe uma consciência específica da liberdade e esta consciência é angústia" (SARTRE, [1943] 1997, p. 19). Não é possível ao homem, portanto, existir sem angústia. Em $O$ ser e o nada surge a concepção de que, apesar de o homem ser angústia, ela não é corriqueiramente percebida, pois no nosso dia a dia quase sempre estamos agindo irrefletidamente.

\section{A angústia não é semobjeto}

Outro filósofo citado por Lacan no seminário $A$ angústia é Martin Heidegger para quem a angústia nos permite recuperar o sentido do ser. Em suas palavras: “a disposição para a angústia é o sim à insistência para realizar o supremo apelo, o único que atinge a essência do homem" (HEIDEGGER, [1929] 1979, p. 49). A essência do homem não é uma substância real, um ente simplesmente dado; por existir, o homem se essencializa na possibilidade da clareira do ser. Dentro de sua exposição no texto Que é metafísica?, Heidegger esclarece que a angústia permite atingir a essência do homem por manifestar o nada.

Por deixar o homem sem referências, sem apoio, a angústia manifesta o nada, que, por sua vez, pertence à essência mesma do ser. Sendo assim, a angústia permite recuperar o sentido de ser humano. Em suas considerações sobre o modo como a angústia nos acossa o nada, Heidegger explicita que a angústia nos corta a palavra e nos dispõe ao espanto do abismo por meio de sua voz silenciosa, da qual não devemos fugir quando pretendemos atingir a essência do ser para o homem. No entanto, Heidegger alerta que não se trata na angústia de tomar o nada como objeto. "O nada se revela na angústia - mas não enquanto ente, nem como objeto. A angústia não é uma apreensão do nada. Entretanto o nada se torna manifesto nela" (HEIDEGGER, [1929] 1979, p. 40). O nada, do ponto de vista heideggeriano, não pode ser o objeto da angústia, pois, na sua proposição, a angústia não tem 
objeto. O que tem objeto é motivo de ansiedade e de temor. Para ele, estamos sempre atemorizados diante de um objeto que nos amedronta. A angústia é radicalmente diferente do temor. $\mathrm{O}$ temor tem um objeto determinado. Na angústia, segundo Heidegger, há uma essencial impossibilidade de determinação, na qual não existe nenhuma referência.

Sigmund Freud em seu texto Inibições, Sintomas e Ansiedade também trabalha na perspectiva de que a característica da angústia é a indefinição e a falta de objeto. Segundo Freud:

o afeto da angústia apresenta uma ou duas características cujo estudo promete lançar muita luz sobre o assunto. A angústia [Angst] tem inegável relação com a expectativa: é angústia por algo. Tem uma qualidade de indefinição e falta de objeto. Em linguagem precisa empregamos a palavra 'medo' [Furcht] de preferência a 'angústia' [Angst] se tiver encontrado um objeto (FREUD, [1926] 2006, p. 160).

A explicitação freudiana da diferença entre medo e angústia, além da precisão quanto à qualidade de indefinição e falta de objeto da angústia, caminha no mesmo sentido da proposição heideggeriana. Contudo, no sentido em que Lacan critica a abordagem heideggeriana da angústia, ele também comenta essa afirmação de Freud do seguinte modo: "é comumente admitido que a angústia seja sem objeto. Isso, que é extraído, não do discurso de Freud, mas de uma parte de seus discursos, é propriamente o que eu retifico por meu discurso. [...] ela não é sem objeto" (LACAN, [1963] 2004, p. 105). Nessa afirmação se encontra o cerne não só da objeção de Lacan a Freud, que, de todo modo, trata-se de uma citação marginal do texto freudiano sobre a angústia, mas de sua objeção ao tratamento heideggeriano do tema da angústia e, mais ainda, o ponto nevrálgico da proposição lacaniana sobre a angústia.

Ao introduzir esse seminário de Lacan, Jacques-Alain Miller observa que "o Seminário $A$ angústia foi feito para explicar, para construir que a angústia não é sem objeto" (MILLER, 2007, p. 28). Lacan acrescenta à sua determinação que esse objeto não é propriamente o objeto da angústia; é o objeto $a$. A angústia lacaniana é a via de acesso ao objeto $a$. Como, para Heidegger, a angústia é sem objeto, Lacan opõe à angústia hedeggeriana a angústia como via de acesso ao objeto $a$. No 
II Congresso de Filosofia da Psicanálise, em 2007, Ricardo Bianchi, em seu texto, Onze teses sobre a angústia, afirma que "a invenção do Dasein, durante Ser e Tempo, corresponde a uma foraclusão do ato, a um rechaço tanto do sujeito barrado, como da queda do resto sob a forma de objeto $a^{\prime \prime}$ (SIMAKE, 2010, p. 6).

Comentadores como Ricardo Bianchi e Jacques-Alain Miller são unânimes no reconhecimento da preferência de Lacan aos trabalhos de Sören Kierkegaard em detrimento da articulação heideggeriana sobre a angústia. O próprio Heidegger no texto de Ser e tempo, no capítulo sobre a angústia, cita o livro Conceito da angústia de maneira elogiosa, dizendo que foi Kierkegaard quem levou mais longe a análise do fenômeno da angústia.

\section{0 conceito de angústia}

A última frase do seminário de Lacan sobre a angústia, sua referência final, articula a psicanálise ao Conceito de angústia de Kierkegaard por meio da relação com o desejo e o objeto $a$. Em seus termos: "convém que o analista seja esse que, por pouco que seja, por algum viés, por alguma borda, tenha feito entrar seu desejo nesse $a$ irredutível para oferecer à questão do conceito da angústia uma garantia real" (LACAN, [1962-1963] 2004, p. 390). A referência ao Conceito da angustia produz uma retomada sobre o conceito de desejo ao articulá-lo ao objeto $a$. Todos os comentadores citados apontam que a referência de Lacan a Kierkegaard se insere em um contexto de retomada da dialética hegeliana tendo em vista que o texto deste último se baseia em uma crítica ao sistema hegeliano. Em seu seminário A angústia, Lacan, ao comentar Hegel, afirma que "a verdade da fórmula hegeliana, é Kierkegaard que a oferece" (LACAN, [1962-1963] 2004, p. 35). Essa verdade é a angústia.

Em Conceito de angústia, a crítica ao sistema hegeliano se pauta nos princípios expostos na Ciência da lógica. Em seus termos, "usa-se na Lógica o negativo como força propulsora que tudo põe em movimento, dado que na Lógica é necessário o movimento, não importa de que modo, custe o que custar, por bem ou por mal" (KIERKEGAARD, [1844] 
2007, p. 18). Kierkegaard aponta que, na lógica, nenhum movimento deverá devir, senão pela força, tal como o faz Hegel. Para ele, Hegel força o movimento que não deveria haver no campo da lógica. Lacan, nesse sentido, comenta que na dialética hegeliana "não tem outra mediação senão a da violência" (LACAN, [1962-1963] 2004, p. 34). O Conceito de angústia, aquilo que não engana, traz a objeção irredutível ao sistema hegeliano.

O cerne do Conceito de angústia é a análise da história de Adão e Eva, tal como a cada geração ela se renova. É uma reflexão sobre a falta, uma releitura da história do pecado original. Segundo Kierkegaard, Adão designa a si mesmo, além do gênero humano, de tal modo que o pecado entra no mundo a cada geração. Contudo, Adão já habitava o pecado sem o saber e ele se descobre como pecador quando fala consigo mesmo. Dá-se, então, a divisão subjetiva de Adão na tomada do significante. Segundo Kierkegaard, "é bastante, portanto, imaginar que Adão falou consigo mesmo. Essa suposição elimina a imperfeição da narração que faz com que alguém fale a Adão daquilo que este não compreende" (KIERKEGAARD, [1844] 2007, p. 54). O centro do problema do pecado original é a angústia. Ela opera quando,

no Gênesis, Deus declara a Adão: “Porém, os frutos da Árvore do Bem e do Mal não comerás", está claro que, no íntimo, Adão não entendia essa frase; porque, como poderia entender a diferença entre o bem e o mal se a diferenciação apenas se fixou após ter sido saboreado o fruto? (KIERKEGAARD, [1844] 2007, p. 53).

A ignorância do significado de bem e mal lhe tornou sensível à angústia ligada a essa designação. A partir desse momento, sua inocência lhe é revelada, mas como falta de saber. Antes de se descobrir como pecador, ele se descobre como inocente. Nem inocência, nem pecado preexistem à intrusão do significante. A partir da intrusão, ele se descobre como inocente, em uma inocência que se apresenta como ignorância ou falta de saber. Daí, ele experimenta a angústia e, finalmente, Adão se torna culpado. "A proibição deixa inquieto Adão, porque nele desperta a possibilidade da liberdade" (KIERKEGAARD, [1844] 2007, p. 53). Adão não compreende o conteúdo da sanção que lhe é feita. É somente certa possibilidade de poder que lhe é apresentada como 
falta para a qual não existe nenhuma representação. Há apenas a consciência de uma possibilidade angustiante de poder, sem que ele saiba o que significa esse poder. Há apenas o sentimento de alguma coisa que perturba, da qual ele se sente culpado. A liberdade desperta a angústia, pois ela é cativa de si mesma como possibilidade que atrai e repele. Na angústia se apresenta uma potência do nada. Livre, então culpado, prisioneiro da alternativa significante. $\mathrm{O}$ pecado hereditário designa a incidência do significante no destino do ser falante, paralelamente, seu ponto de perda. Ao comentar a questão do pecado e da queda a partir do texto de Kierkegaard, Lacan enuncia:

o lugar da alma deve ser situado no nível do a residual, do objeto caído. Não tem concepção viva da alma, com todo o cortejo dramático em que essa noção aparece em nossa cultura, senão acompanhada, do modo mais essencial, da imagem da queda. Tudo o que articula Kierkegaard é apenas referência a esses fundamentos estruturais (LACAN, [19621963] 2004, p. 193).

O comentário de Lacan indica que a imagem da queda proposta por Kierkegaard é ligada à formação do objeto $a$, base de toda a sua articulação no seminário $A$ angústia.

\section{A angústia é um sinal}

Em Inibição, sintoma e angústia, Freud estabelece sua formulação final sobre o tema da angústia com os seguintes termos: "não podemos achar que a ansiedade tenha qualquer outra função, afora a de ser um sinal para a evitação de uma situação de perigo" (FREUD, [1926] 2006, p. 137). Ainda nesse texto, ele especifica o perigo do qual se trata - o perigo vital. Ele acrescenta que o ato do nascimento é a primeira situação de perigo vivida pelo ser humano, um verdadeiro perigo para a vida sem qualquer conteúdo psíquico. Esclarece ainda que a angústia tem uma função biológica indispensável a cumprir como reação a um estado de perigo e que a angústia primordial é tóxica, tendo em vista que "no nascimento é provável que a inervação, ao ser dirigida para 
os órgãos respiratórios, esteja preparando o caminho para a atividade dos pulmões e, ao acelerar as pulsações do coração, esteja ajudando a manter o sangue isento de substâncias tóxicas" (FREUD, [1926] 2006, p. 133). Para ele, quando, posteriormente, a angústia é reproduzida como um afeto, certa perturbação quanto ao bom funcionamento dos órgãos do aparelho respiratório e do coração se apresentam como sinais da angustia primordial.

Em Conceito de angústia, Kierkegaard comenta que as mulheres são muito mais sujeitas à angústia do que os homens por serem mais sensíveis e a sensibilidade é um prenúncio para a aparição da angústia. No parágrafo sobre o efeito da geração, ele acrescenta:

é no momento da concepção que o espírito está mais distante e, por isso mesmo, mas estreitamente se faz sentir a angústia; e é exatamente no seio dessa angústia que se forma o novo ser. Depois disso, no momento de nascer, a angústia atinge seu ponto máximo pela segunda vez na mulher; é nesse instante que o novo ser vem ao mundo. Aliás, a ansiedade que a mulher demonstra durante o parto é coisa muito conhecida. A filosofia tem uma explicação, a psicologia deve possuir a sua. Durante a fase do parto, a mulher atinge outra vez o cume de um dos extremos da síntese, e, por essa razão, o espírito hesita: nesse exato momento, deixa de se fazer notar, está como que suspenso. Contudo, a angústia continua a ser uma medida da grandeza humana e apenas entre os povos inferiores se constatam semelhanças com o parto fácil dos animais (KIERKEGAARD, [1844] 2007, p. 86-87).

Quando Kierkegaard afirma que é no seio da angústia que se forma o novo ser e é no ponto máximo da manifestação da angústia que o novo ser vem ao mundo, sua proposta se coaduna com a freudiana de que a angústia encontra o seu protótipo no ato do nascimento. Essa afirmação se mostra muito importante dentro da abordagem do tema da angústia no contexto da gestação, do parto e do nascimento. No caso específico da gestante e parturiente, ela revive o seu próprio nascimento com a gestação e o nascimento do seu filho.

Os eventos fisiológicos envolvidos no parto sucedem-se de forma diferente nos diversos indivíduos. De um modo geral, no final da gestação (entre a $37^{a}$ e a $42^{a}$ semanas contadas a partir da data do início 
de sua última menstruação), a mulher entra em TP espontaneamente, com raríssimas exceções. As contrações uterinas vão se tornando mais frequentes, com ritmo, intensidade e duração regulares. No início do trabalho de parto, elas são menos intensas, indolores ou pouco dolorosas e os intervalos são maiores; essa fase mais precoce é conhecida como fase latente do trabalho de parto, e dura, em média, 20 horas quando se trata do primeiro filho; nas mulheres que já pariram, sua duração média é de 14 horas. Podem ocorrer ainda uma redução acentuada na movimentação do bebê intraútero e perda de uma secreção catarral ou sanguinolenta pela vagina, chamada tampão mucoso, que, uma vez perdido, consiste no sinal de que o parto não tardará.

Sucedendo a fase latente, começa a fase ativa do trabalho de parto, na qual se completa a dilatação, ou seja, a abertura do canal de parto, já que o útero permanecia fechado durante a gestação. A dilatação necessária para a saída do bebê do útero é de 10 centímetros; mas no início da fase ativa ela era de apenas 3 ou 4 centímetros. Essa fase pode durar a té umas 12 horas até a saída do bebê, ou mais, no primeiro filho. Do segundo parto em diante, sua duração é variável, porém geralmente é menor que no primeiro parto.

As contrações uterinas do trabalho de parto e a saída do bebê têm sido associadas à dor, na maioria dos casos. Mas a maneira como essa dor é percebida varia enormemente. A dor do parto é um meio facilitador de transformações internas do ser mulher. Dor não é, necessariamente, sinônimo de sofrimento. Dor é a forma de se fazer sentir, e, partindo-se desse princípio, pode-se afirmar que ela, sendo inerente ao processo do parto, atua transformando o ser mulher na medida em que permite a percepção da realização de seu mais intenso desejo.

A parturição, todavia, traz um comportamento diferente à mulher por causa de uma diversidade de hormônios presentes em seu sangue em altas taxas, como ocitocina, endorfinas e catecolaminas. Essas substâncias modulam a percepção da dor, tornando-a suportável. Também se relacionam com o prazer, sendo até mesmo euforizantes, como durante o ato sexual e a amamentação. Assim, quando a dilatação do colo uterino já vai adiantada, por volta de 6 a 7 centímetros (transição), a parturiente não deseja falar muito; comunica-se por 
monossílabos, prefere silêncio e local com iluminação baixa. Esse momento de silêncio demarca o ápice do momento de angústia durante o trabalho de parto.

Para Freud, a angústia é um afeto e como um sentimento tem um caráter acentuado de desprazer, cuja presença é difícil de provar, mesmo se encontrando presente. Contudo, ela se faz acompanhar de sensações físicas bem definidas que podem ser referidas mais frequentemente, como já foi apontado, a órgãos específicos do corpo: os órgãos do aparelho respiratório e o coração. Para Freud, a angústia revela um caráter específico de desprazer, atos de descarga e percepções desses atos. Em suas palavras:

um estado de angústia é a reprodução de alguma experiência que encerrava as condições necessárias para tal aumento de excitação e uma descarga por trilhas específicas, e que a partir dessa circunstância o desprazer da angústia recebe se caráter específico. No homem, o nascimento proporciona uma experiência prototípica desse tipo, e ficamos inclinados, portanto a considerar os estados de angústia como uma reprodução do trauma do nascimento (FREUD, [1926] 2006, p. 132).

Mesmo apontando para a sensação de desprazer e para os atos de descarga, Freud propõe o ato do nascimento como protótipo para a sensação de angústia. Daí que, no momento em que a angústia ressurge como um sinal, como expectativa de uma situação de perigo, o sinal é descrito por Freud didaticamente do seguinte modo:

o sinal anuncia: "Estou esperando que uma situação sobrevenha" ou "A presente situação me faz lembrar uma das experiências traumáticas que tive antes. Portanto preverei o trauma e me comportarei como se ele já tivesse chegado, enquanto ainda houver tempo para pô-lo de lado" (FREUD, [1926] 2006, p. 161).

Freud conclui que, por um lado, a angústia é a expectativa do trauma e, por outro, é uma repetição do trauma de forma atenuada. Por se tratar de um afeto e pertencer à consciência, a angústia funciona como um ato de pensar, executado com pequenas quantidades de energia e que tem por objetivo simular o trauma do nascimento. A situação 
traumática é a situação de desamparo. A expectativa do desamparo sofre posteriormente deslocamentos, do perigo para o determinante do perigo, que seria a perda do objeto que surgiu no momento em que a situação de desamparo foi instaurada.

Lacan, ao comentar sobre a proposição freudiana da angústia como um sinal de perigo, enuncia que, a partir de sua própria orientação, o perigo tal como ele o considera "está ligado ao caráter de cessão do momento constitutivo do objeto $a$ " (LACAN, [1962-1963] 2004, p. 375). As implicações dessa proposição lacaniana são múltiplas. Dentre elas se dá a remarcação, por parte de Lacan, do elemento que foi base de articulação em todo o seu seminário, que é a referência da angústia ao momento de produção do objeto $a$.

Em alusão à proposição freudiana do protótipo da angústia no ato do nascimento, Lacan ainda mantém a sua referência à relação da angústia e da cessão do objeto $a$. Pois, quando Freud comenta que o trauma do nascimento se dá no momento da separação da mãe, Lacan acrescenta que não se trata apenas da separação da mãe na origem do trauma do nascimento. No seu entender, o que importa é a separação dos envelopes embrionários e da placenta. Em suas palavras: "é a existência da placenta que oferece à posição da criança no interior do corpo da mãe seu caráter de nidação parasitária" (LACAN, [1962-1963] 2004, p. 195).

Com a fecundação e a formação do ovo, inicia-se o período gestacional, que requer várias modificações no organismo materno para sua adequada adaptação. Tal adaptação é exigida em virtude da interação existente entre os compartimentos materno e fetal. A placenta, órgão de origem fetal, tem função de garantir a nutrição e o desenvolvimento do feto e possui função endócrina; porém, é órgão incompleto na produção de hormônios, necessitando de precursores maternos e fetais. Esse processo de produção hormonal com os três compartimentos - o materno, o placentário e o fetal - é conhecido como "unidade materno-feto-placentária". Assim, quando pensamos em uma mulher gestante, devemos ter em mente que se trata de uma "unidade materno-feto-placentária" e não de uma mulher, ou de uma mãe, ou ainda de um bebê. É a separação dessa unidade que acontece no momento do parto, pois o trabalho 
de parto se instaura quando a placenta envelhece e deixa de cumprir a sua função. Enquanto a progesterona é produzida pela placenta em níveis adequados, é capaz de relaxar o útero e manter a gravidez. Porém, a placenta sofre processo de "envelhecimento" ao final da gravidez, com áreas de calcificação e necrose em sua superfície, reduzindo sua produção de progesterona. Com a queda dos níveis de progesterona, as forças contráteis superam o relaxamento uterino, surgindo, então, as contrações dolorosas e rítmicas que caracterizam o trabalho de parto. Depois disso, só resta parir e nascer. Lacan comenta que:

existem dois cortes tão distantes que eles deixam restos distintos. Para a criança, o corte do cordão deixa separados os envelopes, que são homogêneos a eles, contínuos com seu ectoderme e endoderme. Para a mãe, o corte se localiza no nível da queda da placenta. É mesmo por essa razão que os chamamos de caducos. A caducidade do objeto a está aí, que faz a sua função. A queda, o niederfallen é típico da aproximação de um $a$, portanto mais essencial ao sujeito que toda outra parte dele mesmo (LACAN, [1962-1963] 2004, p. 196).

Cada vez que há possibilidade de produção do objeto $a$, instaura-se o campo de separação e da relação permanente a um objeto perdido. A placenta é um objeto dessa ordem. Como enfatiza Lacan, na queda da placenta, trata-se da produção de um objeto. A queda da placenta está, segundo Lacan, no nível da mãe enquanto a criança perde seus envelopes. Com a queda da placenta, é desfeita a unidade materno-feto-placentária, a perfeição autoerótica se rescinde, a bolsa se rompe e a placenta e os envelopes são os objetos decaídos com os quais ambos, mãe e criança, devem se defrontar. Os caducos, como os nomeia Lacan, formam "a libra de carne" a ser entregue para que um sujeito possa se desprender do corpo.

Na concepção lacaniana, a separação essencial com uma parte do corpo, um apêndice, torna-se simbólica de uma relação fundamental ao corpo próprio para o sujeito alienado desde então. O objeto perdido, o pedaço de carne que nos é arrancado, é o suporte, o substrato autêntico, no sentido aristotélico, de toda função da causa. Assim, o objeto como causa é a parte do corpo sacrificada para o engajamento do ser 
humano na cadeia do significante. Lacan dá o nome de resto a esse objeto causa. A angústia é o único afeto que visa à verdade desse objeto faltante. A angústia, segundo Lacan, "não engana", tendo em vista que todo objeto lhe escapa, pois o objeto a que se refere a angústia surge como causa quando é separado do corpo e para sempre perdido.

Uma vinheta clínica pode explicitar a importância desse objeto $a$ no contexto da cura: paciente de 28 anos demandou uma análise após sucessivas rupturas de relacionamentos amorosos que a deixaram em estado depressivo. Por não mais conseguir trabalhar, sua situação financeira ficou insustentável. A analista indica a busca de um auxílio saúde junto à previdência pública e o retorno para a convivência parental. Ela procurou a previdência pública, mas resistiu à ideia de voltar para a casa dos pais, pois, a cada final de relação, ela retornava e, em um desses retornos, sua mãe a expulsou de casa. A paciente guarda uma mágoa muito grande da mãe por isso e por todo o tratamento que ela lhe dedicou desde criança.

A sua mãe é uma paciente submetida a tratamento psiquiátrico e diagnosticada como bipolar. Com o trabalho de análise, ela foi entendendo as variações de humor da mãe e podendo aceitar melhor o seu comportamento. Mesmo assim, não quis retornar para a convivência familiar e foi morar com outro companheiro. Esse último, por sua vez, não suportou seu comportamento depressivo e a expulsou de casa, fato que a levou a uma tentativa de suicídio. Arrependido, ele a convidou para voltar e ela aceitou, até que saiu por sua própria conta para morar com a família. Com isso, ela se sentiu um pouco melhor, mesmo sem sair do estado depressivo. Ficar próxima à sua mãe lhe fazia bem, mas ainda faltava algo que ela não sabia o que era. Um dia, em sessão de análise, a analista lhe perguntou o que ela realmente queria. E, de modo muito claro e preciso, a paciente lhe disse que não queria estar exatamente próxima de sua mãe, ela queria algo além da sua mãe, ela queria a placenta.

No contexto de uma cura, a cada vez que um paciente se depara com uma das versões do objeto $a$ que causa o seu desejo, apresenta-se uma possibilidade de mudança subjetiva. Diante do ensinamento sobre a relação do sujeito com um objeto causa de desejo proporcionado 
por essa referência à clínica de orientação lacaniana, pretendo finalizar com a última frase do seminário $A$ angústia de Lacan que não me canso de admirar e repetir: "convém asseguradamente que o analista seja aquele que, pouco que seja, por qualquer viés, por qualquer borda, tenha feito entrar seu desejo nesse $a$ irredutível para oferecer à questão do conceito de angústia uma garantia real".

\section{Referências}

FREUD, S. O inconsciente. In: FREUD, S. Edição standard brasileira das obras completas de Sigmund Freud. Rio de Janeiro: Imago Editora, 2006. v. 14. Publicado originalmente em 1915.

FREUD, S. Inibições, sintomas e ansiedade. In: FREUD, S. Edição standard brasileira das obras completas de Sigmund Freud. Rio de Janeiro: Imago Editora, 2006. v. 20. Publicado originalmente em 1926.

HEIDEGGER, M. Ser e tempo. Petrópolis: Vozes, 1997. Publicado originalmente em 1928.

HEIDEGGER, M. Que é metafísica? São Paulo: Abril Cultural, 1979. Publicado originalmente em 1929.

KIERKEGAARD, S. O conceito de angústia. São Paulo: Hemus, 2007. Publicado originalmente em 1844.

LACAN, J. Le Séminaire: livre X - l'angoisse. Paris: Seuil, 2004. Publicado originalmente em 1962-1963.

MILLER, J.-A. A propósito dos afetos na experiência analítica. In: KALIMEROS. As paixões do ser: amor, ódio e ignorância. Rio de Janeiro: Contra Capa, 1998.

MILLER, J.-A. La angustia: introducción al Seminario X de Jacques Lacan. Madrid: López de Hoyos, 2007.

SARTRE, J. P. Esboço de uma teoria das emoções. Porto Alegre: L\&PM, 2006. Publicado originalmente em 1939. 
SARTRE, J. P. O ser e o nada: ensaio de ontologia fenomenológica. 2. ed. Petrópolis: Vozes, 1997. Publicado originalmente em 1943.

SIMAKE, R. T. et al. Onze teses sobre a angústia. São Carlos: EdUFScar, 2010.

Recebido: 23/06/2011

Received: 06/23/2011

Aprovado: $21 / 07 / 2011$

Approved: 07/21/2011 